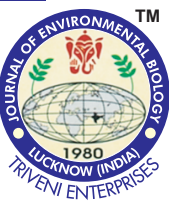

\title{
Measuring surface water salinity of Pearl River Estuary by MODIS 250-m imageries
}

\begin{tabular}{lll}
\hline Paper received: 17. 04. 2018 & Revised received: 14.11 .2018 & Accepted: 03.01 .2019 \\
\hline
\end{tabular}

\section{Authors Info \\ L. Fang ${ }^{1,2,3 *}$, Z. Liu', S. Chen ${ }^{2}$ and W. Huang ${ }^{3,4}$ \\ ${ }^{1}$ Jiangsu Province Support Software Engineering R\&D Center for Modern Information Technology Application in Enterprise, Suzhou, 215104, China \\ ${ }^{2}$ Guangdong Open Laboratory of Geospatial Information Technology and Application, Guangzhou Institute of Geography, Guangzhou, 510070, China \\ ${ }^{3}$ Department of Civil Engineering, Florida State University, \\ Tallahassee, FL 32310, USA \\ ${ }^{4}$ Key Laboratory of Yangtze River Water Environment, Ministry of Education, Tongji University, Shanghai, 200092, China \\ *Corresponding Author Email : fanglg@jssvc.edu.cn}

\section{Edited by}

Prof. Muhammad Aqeel Ashraf

Reviewed by

Dr. Keqing Li

Dr. Dan Li

\begin{abstract}
Aim: Moderate resolution imaging spectroradiometer (MODIS) 250-m imageries were used to evaluate the performance for developing the effective model of salinity using field spectra, the absorption coefficient of color dissolved organic matter $\left(a_{\text {coom }}\right)$ collected on October 21and November 2, 2012 in the Pearl River Estuary (PRE), China.
\end{abstract}

Methodology: Remote sensing reflectance of the four simulated MODIS bands $\left(R_{r s}(B i)\right)$ with $a_{\text {cDom }}(\lambda)$ data were used for algorithms development, which include least squares regression of the single band, difference between bands, band ratios, sediment index and their varieties with $a_{\text {сDом }}(\lambda)$ based on the dataset of November 2, 2012 ( $N=18)$. Additionally, the model of salinity with $a_{\text {CDom }}(\lambda)$ data was also calibrated $(N=18)$.

Results: Results illustrated the optimum performance of quadratic model of sediment index for estimation of $a_{\text {CDOM }}(355)\left(R^{2}=0.67, N=18, P<0.001\right)$, and the reverse linear model of $a_{\text {CDOM }}(355)$ is of the best accuracy for estimation of salinity $\left(R^{2}=0.83, N=18, P<0.001\right)$. An effective method to estimate surface water salinity from simulated MODIS 250-m bands was calibrated and validated using the independent dataset of October 21, 2012 (RMSE $=1.95 \%, M R E=9.65 \%, N=17$ ) in the Lingding Bay of PRE. The preferred models were further applied to retrieve $a_{\text {сDom }}(355)$ and salinity data from the MODIS 250-m data in the coastal and inner Lingding Bay of PRE. The result presented rationality of salinity distribution of PRE. The MODIS 250-m salinity mapping was validated based on in-situ measurements, and presented a good salinity mapping accuracy (RMSE $=1.72 \%$, MRE $=8.24 \%, N=10)$. The study proved the robustness of these algorithms for $a_{\text {CDom }}(355)$ and salinity estimation in the coastal and inner Lingding Bay of PRE by MODIS remote sensing.

Interpretation: Therefore, the effective method can be applicable in detecting variability of CDOM concentration and salinity during tidal cycle in a high frequency (two times during daytime), which proves the detection ability of MODIS 250-m imageries in estuarine and coastal waters. It provides the water supply and conservancy authorities spatially and temporally understand the marine intrusion in the Lingding Bay of PRE.

Key words : Color dissolved organic matter, MODIS 250-m, Pearl River Estuary, Salinity

Citation: F., Ligang, Z. Liu, S. Chen and W. Huang: Measuring surface water salinity of the Pearl River Estuary from MODIS 250-m imageries. J. Environ. Biol., 40, 472-485 (2019). 


\section{Introduction}

Marine intrusion into rivers is seasonal and periodic hydrological event in the coastal estuary area, which usually occurs in the winter with few freshwater inflow. The dynamic forcing of marine intrusion is caused by the change of fresh water inflow, tidal amplitudes, wind speed and wind direction. In recent years, due to global change acceleration (sea levels rise, drought, population explosion, economic development and so on), marine intrusion in the Pearl River riverway appears earlier, lasts longer and involves more cities (Yin et al., 2006; Jamal et al., 2018). The invasion of sea water has brought a lot of harm: the increase in salinity in the freshwater affects industrial and agricultural water first, distribution of nutrients in water next, which changes the environment in estuarine ecosystem (D'Sa et al., 2000; Mao et al., 2004; Xiao and Liu, 2018). Common method for marine intrusion is measuring salinity of time series at a station, which need a large number of stations and long-term data for PRE. Common method cannot monitor spatial change during the marine intrusion and cannot meet the needs of the water supply and conservancy authorities in the PRE. Based on effective approaches for spatial and temporal salinity simulation, contributes to understand the principle and method of sea water intrusion into estuarine ecosystems.

Remote sensing data has the ability to provide synoptical view of water quality of the entire coastal region of interest. More over new age satellite sensors have the ability to provide remote sensing picture of the earth surface in every 24 hours. Thus, continuous monitoring of surface water in costal environment is possible in a daily frequency. The theoretical basis for studying the salinity of water bodies by means of remote sensing, is the inverse correlations found between color dissolved organic matter (yellow substance) and salinity in coastal seas (Jerlov, 1968; Mckee et al., 1999). Because of the distinct optical signal of CDOM in the visible spectrum (Bricaud et al., 1981; Bricaud et al., 2012; Doerffer and Schiller, 2007; Lee et al., 2010; Tilstone et al., 2012; Werdell et al., 2013; Abbas et al., 2018). Therefore, it is feasible to interpret remote sensing ocean color in terms of salinity, from an aircraft or satellite.

Some researchers demonstrated that the multispectral images to be transmitted from this multispectral scanner would be useful in the identification and delineation of the runoff-influenced waters found along the west coast of Ireland (Monahan and Pybus, 1978). Some researchers found an opposite relationship between $\mathrm{CDOM}$ and salinity and defined the relationships in the Clyde Sea (Bowers et al., 2000; Chuanlei et al., 2018). Other researchers got the satisfactory estimation of $\mathrm{CDOM}$ and salinity in the Clyde Sea from remote sensing ocean color based on two key optical characteristics in some regions of freshwater inflow. First, CDOM has the strong effect on ocean color with relatively high concentrations. Next, the significant relationship exists between salinity and CDOM originating from fresh water inflow
(Binding and Bowers, 2003).

Recent work in coastal ocean waters indicates the bandratio algorithms of water reflectance can be applied to recover the absorption coefficient of CDOM (D'Sa and Miller, 2003; D'Sa et al., 2006; Castillo and Miller, 2007; Johannessen et al., 2003; Mannino et al., 2008; Naik et al., 2011; Shanmugam, 2011; Mannino et al., 2014; Razzak et al., 2018). Several studies of optical and fluorescent characteristics of CDOM and salinity have been also reported in the PRE (Chen et al., 2003; Chen et al., 2004; Hong et al., 2005; Fang et al., 2010; Fang et al., 2009). Chen et al. (2003) simulated distribution of yellow substance using Sea-viewing Wide Field-of-view Sensor (SeaWiFS) in the Lingding Bay of PRE (Chen et al., 2003; Kibria et al., 2018).

Fang et al. $(2009,2010)$ validated the models between total suspended solids and spectra of surface water in different salinity ranges and developed the methods to monitor salinity distribution of surface waters from Earth Observing-1 Advanced Land Imager and Hyperion satellite imageries in the PRE (Fang et al., 2010; Fang et al., 2009). However, based on remote sensing technology, the salinity simulation of the Pearl River estuary is still limited by the factors such as the satellite operating cycle and weather factors, in addition, the sensors with low spatial resolution are not capable of detecting marine intrusion. The existing models of salinity prediction from remote sensing imageries cannot meet the needs of marine intrusion management in the PRE.

The MODIS 250-m data is particularly suitable for ocean color remote sensing thanks to its twice daily coverage and appropriate spatial resolutions for sediment migration. Some recent models have been developed for retrieving CDOM in the optically complex estuarine water based on MODIS. A group scientist found that field remote sensing reflectance values were significantly correlated to CDOM, and successfully derived CDOM absorption from a MODIS band-ratio algorithm in NW Florida estuaries (Schaeffer et al., 2015). Others group researcher detected the slope change of linear relationship between CDOM and salinity with position (salinity range: 24\%o-32\%o) within the Bay (Hu et al., 2004).

Some researchers developed and validated ocean color satellite algorithms for the estimation of $a_{C D O M}$ in the estuarine and continental shelf waters along the northeastern U.S. coast (Mannino et al., 2008). However, there are not many research of MODIS-related algorithms for spatial mapping salinity field, especially in the PRE. Therefore, the objectives of our study are (1) to develop an algorithm using in-situ measurements and simulated MODIS bands from our study region, (2) examine the negative correlation between salinity and CDOM originating from fresh water inflow in the PRE, (3) validate these algorithms for 250-m spatial resolution MODIS data, and (4) estimate surface water salinity and map its rationality in the Lingding Bay of PRE. 


\section{Materials and Methods}

Study area: The PRE-is a partially mixed estuary and influenced by tidal current from the Pacific Ocean. Tides invade through the Luzon Strait with tidal range of 0.8-1.63 m (Ye and Preiffer, 1990). The Pearl River is famous in the world with annual runoff of $3.2610^{12} \mathrm{~m}^{3}$. Suspended sediment load of Pearl River is about $7.110^{11} \mathrm{~kg}$. Marine intrusion into rivers usually occurs in the dry season (November to January of next year) with small freshwater discharges in the PRE. The Pearl River Estuary is with welldeveloped river system and a lot of tributaries. The shape of Lingding Bay is an inverted funnel. The north side is relatively narrow and the south side is relatively wide. There are four outlets, located from the north to south of the Bay (Chen et al., 2005).

Data collection and processing: The field sampling time is from 9:30 to 14:30 on October 21and November 2, 2012 (Fig. 1). In situ measurements and water sampling from 10 locations are synchronous with MODIS satellite imagine time. Salinity of

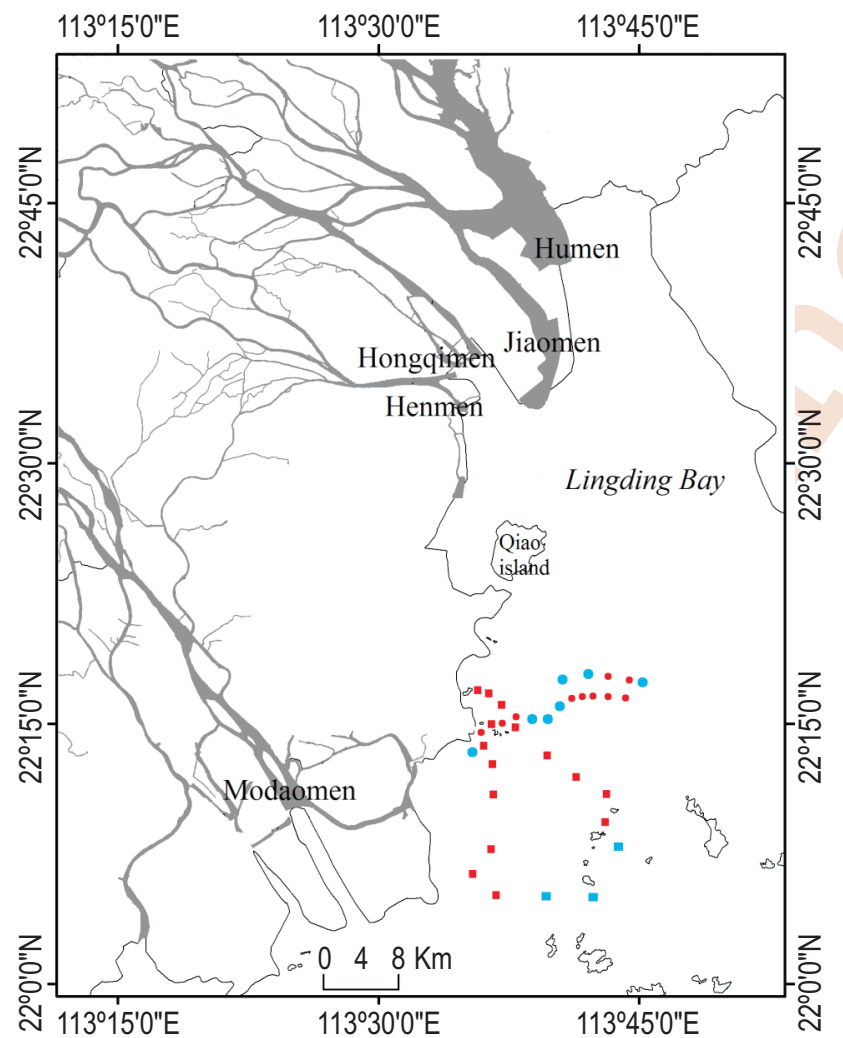

Fig. 1 : Map of river network. There are eight river outlets in the Lingding Bay. Samples for spectrum, salinity, temperature, transparency and absorption coefficient of CDOM were collected and processed on October 21 (17 sampling stations) and November 2 (18 sampling stations), 2012. Blue shapes indicate ten sampling sites, synchronously collected between the Terra MODIS and Aqua MODIS overpass, including salinity data from seven in-situ samples on October 21, 2012 and three in situ samples on November 2, 2012. surface water was measured on the spot using a portable meter (YSI ${ }^{\circ} 30 /$ Set). Exact locations of sampling stations were measured by high precision global positioning system (RMSE < $10 \mathrm{~m})$. Water samples were collected and stored in cooler polypropylene bottles and transported to the laboratory within $4 \mathrm{~h}$. Water quality of each sample was analyzed in South China Sea Institute of Oceanology, Chinese Academy of Sciences. Collection, storage, and measurement of sample was carried out in line with the Technical Specifications Requirements of Surface Water of China.

The field spectral measurement of water was carried out with an ASD Field Spec spectroradiometer manufactured by Analytical Spectral Devices., Inc. The spectroradiometer works in the bands ranging from 350 to $2,500 \mathrm{~nm}$ at increments of $1.4 \mathrm{~nm}$ from 350 to $1,000 \mathrm{~nm}$ and $2 \mathrm{~nm}$ from 1,000 to $2,500 \mathrm{~nm}$ with a field view of $25^{\circ}$. The spectral resolution can be interpolated into $1 \mathrm{~nm}$ by the specific tool of the spectroradiometer. To effectively reduce the shadow of the boat and the influence of solar radiation, observation azimuth angle of the spectroradiometer is $130^{\circ}$ (zero degree of solar azimuth angle), and observation zenith angle is controlled between $30^{\circ}$ and $45^{\circ}$. The adopt of an observation angle can eliminate influence of direct sunlight and avoid the interference of boat's shadow. In the spectral measurements of each station, radiance of surface water $\left(L_{\text {sw }}\right)$, standard gray board $\left(L_{p}\right)$ and skylight $\left(L_{s k y}\right)$ were measured in order. Integral time of the spectroradiometer was $172 \mathrm{~ms}$, and ten spectral records were continuously acquired for each target. The entire field measurements procedure was according to the Ocean Optical Protocols (Revision 3) by National Aeronautics and Space Administration (Muerller and Fargion, 2002).

Generally, reflectance of remote sensing $\left(R_{r s}\right)$ of water is calculated by ratio of water-leaving radiation and total incident radiant flux of surface water (equation (1)).

$$
\operatorname{Rrs}=\frac{L_{w}(\lambda)}{E_{d}\left(\lambda, 0^{+}\right)}
$$

where $L_{w}(\lambda)$ refers to water-leaving radiation ( $\lambda$ stands for wavelength). $E_{d}\left(\lambda, 0^{+}\right)$refers to total incident radiant flux of surface water.

$L_{w}(\lambda)$ refers to spectral information of water, which is reflected by the water-air interface, and $L_{w}(\lambda)$ can be calculated by equation 2.

$$
L_{w}(\lambda)=L_{s w}(\lambda)-r L_{s k y}(\lambda)
$$

where $L_{s w}(\lambda)$ is total radiation of surface water, $L_{\text {sky }}$ is from the diffused radiance of the sky, and $r$ is reflectance of the skylight from the water-air interface (Mobley, 1999).

The value of $r$ is decided by the solar azimuth, the roughness of surface water and wind speed, and so on. The wind speed was not more than $4 \mathrm{~m} \mathrm{~s}^{-1}$ during field sampling, thus, the 
Table 1: Date and location of field measurement and sampling in the studied area

\begin{tabular}{llllll}
\hline Data & Location & Samples & Model calibration & Model validation & MODIS imageries validation \\
\hline $21 / 10 / 2012$ & Lingding Bay & 17 & 0 & 17 & 7 \\
$2 / 11 / 2012$ & Lingding Bay & 18 & 18 & 0 & 3 \\
In total & & 35 & 18 & 17 & 10 \\
\hline
\end{tabular}

Table 2: Statistics characteristic of the absorption coefficient of CDOM and salinity collected from the Pearl River Estuary

\begin{tabular}{lllll}
\hline & Maximum & Minimum & Mean & StdDev \\
\hline Temperature $\left({ }^{\circ} \mathrm{C}\right)$ & 26.9 & 22.0 & 25.2 & 1.2 \\
Salinity $(\%)$ & 20.11 & 12.59 & 16.03 & 1.94 \\
Transparency $(m)$ & 1.2 & 0.4 & 0.8 & 0.2 \\
$a_{\text {CD M }}(440)\left(\mathrm{m}^{-1}\right)$ & 0.3725 & 0.1516 & 0.2562 & 0.0499 \\
$a_{\text {сDом }}(400)\left(\mathrm{m}^{-1}\right)$ & 0.5970 & 0.2755 & 0.4473 & 0.0796 \\
$a_{\text {CD M }}(355)\left(\mathrm{m}^{-1}\right)$ & 1.2354 & 0.6276 & 0.9926 & 0.1799 \\
\hline
\end{tabular}

value of r was set as 0.021 (Tang et al., 2004).

$$
E_{d}\left(\lambda, 0^{+}\right)=\frac{\pi L_{p}(\lambda)}{P_{p}(\lambda)}
$$

where $L_{p}(\lambda)$ is the radiance of standard $30 \%$ gray board and $P_{p}$ $(\lambda)$ is the reflectance of the gray board.

Samples of surface water were analyzed in the laboratory within $24 \mathrm{hr}$ after field sampling. The absorption coefficient of CDOM was measured and calculated by the advanced Gelbstoff Optical Analysis Laboratory System.

The set from two different days containing 35 water samples, which were analyzed in the study (Table 2). 17 samples were picked from PRE-on October 21, 2012. The salinity ranges from $14.18 \%$ to $18.66 \%$, and the corresponding average value is $16.35 \%$. 18 water samples were collected from PRE-on November 2, 2012. The salinity ranges from $12.59 \%$ to $20.11 \%$, and the corresponding average value is $15.68 \%$. CDOM absorption coefficient at $355 \mathrm{~nm}$, the range of $a_{\text {CDOM }}$ (355) is from $0.6276 \mathrm{~m}^{-1}$ to $1.2354 \mathrm{~m}^{-1}$. CDOM absorption coefficient at $400 \mathrm{~nm}$, the range of $a_{\text {CDOM }}(400)$ is from $0.2755 \mathrm{~m}^{-1}$ to $0.5970 \mathrm{~m}^{-1}$. CDOM absorption coefficient at $440 \mathrm{~nm}, a_{\text {сDом }}(440)$ ranges from 0.1516 $\mathrm{m}^{-1}$ to $0.3725 \mathrm{~m}^{-1}$.

Reflectance data and processing: To analyze the spectral characteristic of different stations, some spectral reflectance was selected and presented in Fig. 2. There was a peak near $575 \mathrm{~nm}$ in spectral variation of $R_{r s}$ for all spectral curves. Then, it was a rapid drop in the blue band because of the strong absorption by particulate matter and dissolved materials. In general, within MODIS 250-m spectral $R_{r s}(B 1)(614-682 \mathrm{~nm})$ the light backscattering from suspended substance mainly work for the reflectance of surface water, as a result of powerful absorption by pure water and CDOM (Petus et al., 2010). However, all spectral curve presented an accelerated decline from $650 \mathrm{~nm}$, especially near the band of $657 \mathrm{~nm}$, which is central wavelength of first band

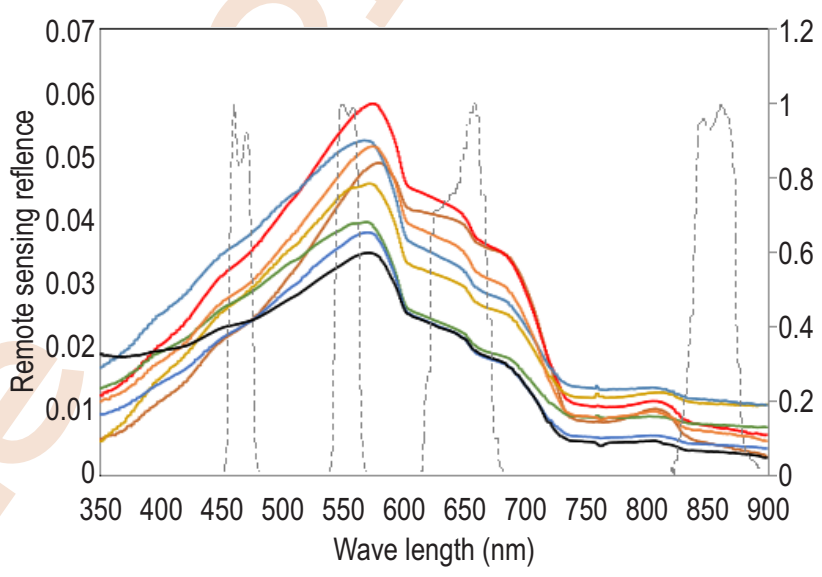

Fig. 2 : Spectral reflectance of some stations (MODIS 250-m $R_{r s}(\mathrm{Bi})$ was presented by dotted line).

of MODIS 250-m. Previous studies showed particle scattering would decrease when increasing particle sizes due to decreasing particle scattering efficiency, and the increase of particle sizes was owing to the increase of organic matter (Binding et al., 2009). It illustrates that the change of CDOM can be explained by $R_{r s}(\mathrm{~B} 1)$ in the study area. Within MODIS 250-m spectral $R_{r s}$ (B2) (820-902 $\mathrm{nm})$, lower spectral values in $R_{r s}(\mathrm{~B} 2)$ than $R_{r s}(\mathrm{~B} 1)$ are due to the strong absorption by pure water (Hale and Querry, 1973; Pope and Fry, 1997; Smith and Baker, 1981). The relationship between the magnitude of the reflectance spectra and the change of CDOM absorption coefficient is Complex and implicit. Thus, it is difficult to retrieve CDOM absorption coefficient using the common single bands models.

To evaluate the performance of MODIS imagery for marine intrusion in the PRE, the 18 in situ reflectance $\left(R_{r s}()\right)$ on November 2, 2012, were transformed to MODIS 250-m reflectance data according to MODIS 250-m response functions 
using Eq. (4):

$$
\operatorname{Rrs}(B i)=\frac{\sum_{\lambda 1}^{\lambda n} S(\lambda) \operatorname{Rrs}(\lambda)}{\sum_{\lambda 1}^{\lambda \mathrm{n}} \mathrm{S}(\lambda)}
$$

where, $\lambda 1$ and $\lambda n$ are minimum and maximum of the corresponding band $i$ of MODIS ( $i=1,2,3$ and 4$). S(\lambda)$ is the spectral response function of MODIS 250-m image. Thus, the four Rrs data (Rrs(B1), Rrs(B2), Rrs(B3) and Rrs(B4)), corresponding to the four MODIS $250-\mathrm{m}$ band values, were simulated in each sampling station.

Satellite data and processing: MODIS is an important spectroradiometer on the Terra and Aqua satellites. Terra satellite was successfully launched on December 18, 1999, and it passes south to north over the equator at about half past ten in the morning. Aqua satellite was launched on May 4, 2002, and it passes from south to north across the equator at about 13:30 h. MODIS Terra and Aqua are recording images of global surface every one to two days, acquiring important spectral data of different wavelengths (URL: http://modis.gsfc.nasa.gov/). Wavelengths of these data range from $0.4 \mu \mathrm{m}$ to $14.4 \mu \mathrm{m}$ and is divided into 36 bands. These data can be used for monitoring of the land, ocean, and atmosphere of troposphere. Two bands in 36 bands (band1 and band2) are recorded at image resolution of 250 $\mathrm{m}$, with five following bands (band3-band7) at $500 \mathrm{~m}$.

MOD09GQ and MYD09GQ provide Bands 1 and 2 at a 250-meter spatial resolution. surface reflectance of Bands 1 and 2 are provided by Science Data Sets. The center wavelength of band 1 is at $645 \mathrm{~nm}$ and band 2 at $859 \mathrm{~nm}$. MOD09GA and MYD09GA are the reflectance products of global surface. Their spatial resolution is $500 \mathrm{~m}$ including bands 3 and 4 centered at 555 and $469 \mathrm{~nm}$. These data were employed to estimate the absorption coefficient of CDOM and salinity using the models in the work.

MODIS 09 products were selected across the PRE on October 21 and November 2, 2012. Because of the high cloud cover (average cover of 70\%) on 2 November 2012 for Aqua data, less or free cloud images from 21 October 2012 and 2 November 2012 aboard on Terra, 21 October 2012 aboard on Aqua, were selected to evaluate the performance of marine intrusion models in the PRE.

The geometric correction is one of the most important step in MODIS preprocessing, which was carried out by the MODIS Reprojection Tool. In order to facilitate visualization and analysis, First, image contrast was enhanced by the software (Environment for Visualizing Images, version 4.6). Second, 250m spatial resolution data at 555 - and $469-n m$ can be generated by interpolating of the 500-m resolution data based on an image sharpening tool. Then, MODIS 250-m Red-Green-Blue images were composed by the 645-, 555-, and 469-nm bands data.
Finally, reflectance of satellite remote sensing $\left(R r s_{\text {sat }}(\mathrm{Bi})\right)$ can be calculated by geolocated $D N_{\text {sat }}(\mathrm{Bi})$ using Eq. (4) (Petus et al., 2010).

$$
\operatorname{Rrs}_{\text {sat }}(B i) \approx D N_{\text {sat }}(B i) /(10000 * \pi)
$$

According to the feature of image, Specific region of interest were created with ROI tools of ENVI. Reflectance values at specific latitude and longitude where the sampling have been conducted were collected from the images. To reveal the spectral characteristics of sea water and land, Z-profile on MODIS image was conducted, and water-sensitive bands can be found. In order to reduce other interferences further, the ground and water body were removed based on binary mask.

\section{Results and Discussion}

Relationship between $R_{r s}(\mathrm{Bi})$ and $\mathrm{a}_{\text {cDom }}(\mathrm{I})$ : The relationship between remote sensing reflectance of the four MODIS bands $\left(R_{r s}\right.$ (Bi)) and the CDOM absorption coefficient $\left(a_{C D O M}(I)\right)$, including the single band, band ratios and their varieties, were calibrated based on regression analysis based on the dataset of 2 November, 2012 (the number of samples $(N)$ is 18). The Preliminary analysis showed the poor relationship between $a_{\text {CDOM }}(440), a_{\text {CDOM }}(400)$ and $R_{\mathrm{rs}}(\mathrm{Bi})$ due to lower values of the absorption coefficient (the maximum value of $\left.\mathrm{a}_{\mathrm{CDOM}}(400)<0.6\right)$ during field measurements in the PRE. Thus, the relationship between $a_{\text {CDOM }}(355)$ and $R_{r s}(\mathrm{Bi})$ was focused on.

Linear and quadratic models were presented as shown in Fig. 3 including single band, band ratio, and sediment index. The other models were not showed in the paper due to $R^{2}<0.1$. The significant correlations between spectral varieties and the $a_{C D O M}$ (355) were presented as shown in the Fig.3 (C-F). The quadratic models of $R_{r s}(\mathrm{~B} 2) / R_{r s}(\mathrm{~B} 1)$ and sediment index got the higher calibration accuracy in all models, explaining more than $66 \%$ of the $a_{C D O M}(355)$ variation in the PRE. The results are different with previous work. Existing research on $a_{C D O M}$ models development and verification recommended the band-ratio model of $R_{r s}(443) /$ $R_{r s}(555)$ for coastal region waters (Mannino et al., 2008), $R_{r s}(490)$ $/ R_{r s}(555)$ for the southern Middle Atlantic Bight (Mannino et al., 2008), $R_{r s}(490) / R_{r s}(665)$ for the Clyde sea (Binding and Bowers, 2003). Recently, Mannino et al. (2014) applied the non-linear models with some different band ratios including $R_{r s}(412) / R_{r s}$ (555), $R_{r s}(412) / R_{r s}(547)$ and $R_{r s}(412) / R_{r s}(670)$ etc. also yielded very good estimation for the measurements for $a_{C D O M}(412)$ and $a_{\text {CDOM }}(355)$. Although these algorithms are highly sensitive to the lower $a_{C D O M}$ values, which is typical of nearshore waters, such as Hudson River Estuary, the western Gulf of Maine and Chesapeake Bay, they are low sensitive to the higher $a_{\text {CDom }}$ values in these study regions (Mannino et al., 2014). Therefore, it shows clearly that specific band-ratio model would not be used for different regions. There are different sensitive bands in the different region. 

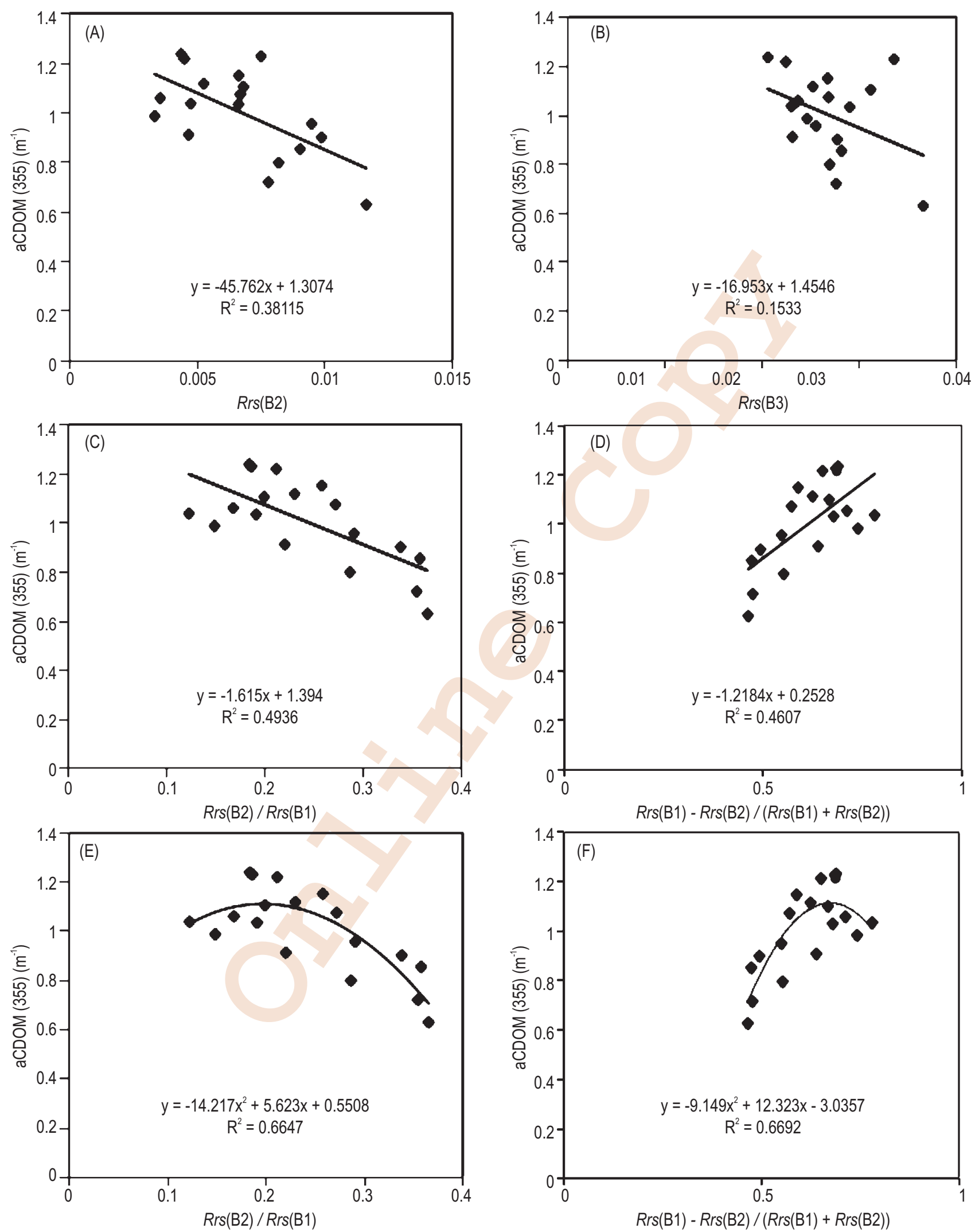

Fig. 3: Comparison of regression models of CDOM absorption coefficient $\left(\mathrm{m}^{-1}\right)$ in the form of single band, sediment index and band ratio $(N=18,0.6276$ $\left.1.2354 \mathrm{~m}^{-1}\right)$. 
Table 3: Station locations, $a_{\text {CDom }}$ (355), salinity and transparency data on November 2, 2012 in the Lingding Bay of PRE

\begin{tabular}{|c|c|c|c|c|c|}
\hline Station\# & Longitude $\left({ }^{\circ}\right)$ & Latitude $\left({ }^{\circ}\right)$ & $a_{\text {cDom }}(355)\left(m^{-1}\right)$ & Salinity (\%o) & Transparency (m) \\
\hline 1 & 113.6368 & 22.2523 & 1.0356 & 12.59 & 0.4 \\
\hline 2 & 113.6619 & 22.2226 & 1.2273 & 13.22 & 0.8 \\
\hline 3 & 113.6887 & 22.2073 & 0.9545 & 16.16 & 0.8 \\
\hline 4 & 113.7187 & 22.1891 & 0.8991 & 17.92 & 1 \\
\hline 5 & 113.7167 & 22.1625 & 0.7969 & 18.12 & 1.1 \\
\hline 6 & 113.7261 & 22.1385 & 0.6276 & 20.11 & 1.1 \\
\hline 7 & 113.7041 & 22.0888 & 0.8523 & 19.69 & 1.2 \\
\hline 8 & 113.6568 & 22.0879 & 0.7187 & 19.62 & 1 \\
\hline 9 & 113.6088 & 22.0912 & 0.9097 & 16.2 & 0.8 \\
\hline 10 & 113.5891 & 22.1126 & 1.0317 & 14.76 & 0.5 \\
\hline 11 & 113.6072 & 22.1417 & 1.0579 & 14.13 & 0.7 \\
\hline 12 & 113.6094 & 22.1888 & 0.9847 & 15.56 & 0.7 \\
\hline 13 & 113.6111 & 22.2227 & 1.1155 & 14.94 & 0.8 \\
\hline 14 & 113.6013 & 22.2367 & 1.1028 & 14.18 & 0.6 \\
\hline 15 & 113.6143 & 22.2547 & 1.1489 & 13.87 & 0.9 \\
\hline 16 & 113.6204 & 22.2726 & 1.2167 & 14.18 & 1.1 \\
\hline 17 & 113.6082 & 22.2858 & 1.0722 & 14.02 & 0.9 \\
\hline 18 & 113.5959 & 22.2903 & 1.2354 & 12.97 & 0.6 \\
\hline
\end{tabular}

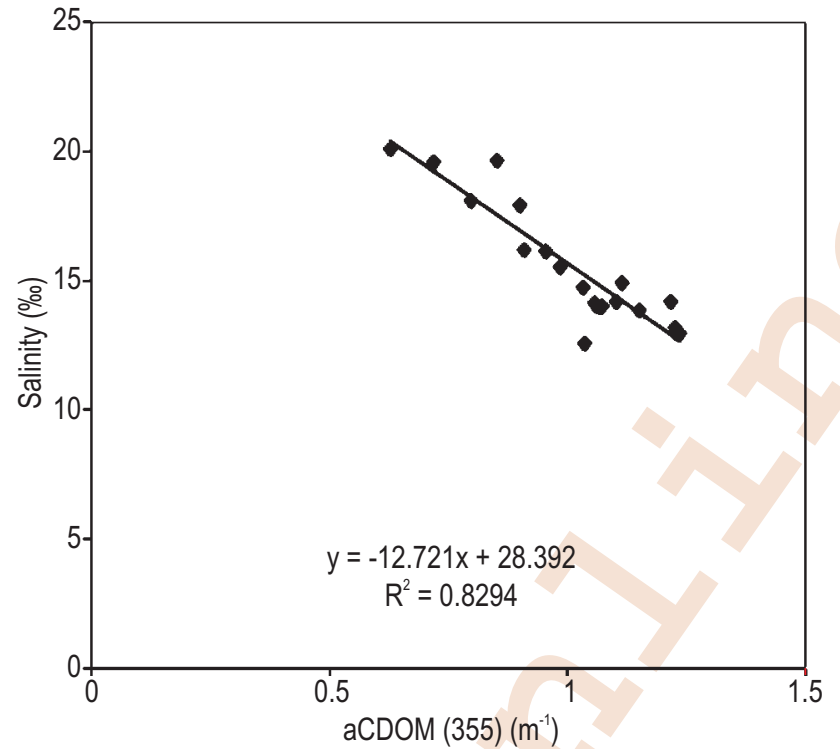

Fig. 4 : Relationship between $\mathrm{a}_{\text {cDom }}(355)\left(\mathrm{m}^{-1}\right)$ and salinity $(\%)$ based on the dataset of 2 November, 2012 (the number of samples $(N)$ is 18 , and the salinity range is $12.59-20.11 \%$ ).

Bowers et al. (2000) theoretically proved a linear relationship between the CDOM absorption coefficient and band ratio of red light to other color, when the contribution of suspended substance is weaker than that of CDOM on the optical signature (Bowers et al., 2000), and the magnitude of $\mathrm{a}_{\text {сDom }}(\lambda)$ relates to its source and composition, which is different in the different waters (Mannino et al., 2014).. Thus, the Fig. 3 (C) demonstrated that the optical signature of CDOM was stronger during the field measurements in the PRE, which showed the estuarine environment was affected by artificial particless and dissolved matter (Xia et al., 2004).

Relationship between $a_{\text {cDom }}(355)$ and salinity: The correlation between $a_{\text {CDOM }}(355)$ and salinity was analyzed from field data on November 2, 2012 (table 3). There is significant correlation between $a_{C D O M}(355)$ and salinity as shown in the Fig.4. $a_{\text {CDom }}(355)$ increases linearly with the decreasing salinity. Equation (6) describes the correlation including 18 sample data with a good linear correlation $\left(R^{2}=0.83\right)$.

Salinity $=-12.721 \times a_{\text {CDOM }}(355)+28.392(R 2=0.83, N=18$
$P<0.001)$ where $a_{\text {CDOM }}(355)$ is the CDOM absorption coefficient at $355 \mathrm{~nm}$.

Usually, a linear correlation between $a_{C D O M}$ (355) and salinity in estuary, indicates that CDOM is from upstream freshwater (Hong et al., 2005). With rapid economy development and population increase in the Pearl River Drainage Area, dissolve organic matter and organic suspended matter accumulate in the river. Therefore, CDOM was rooted from upstream and the nearby cities and villages in the PRE. However, the reverse linear correlation between $a_{\text {CDOM }}(355)$ and salinity is regional, and its slope depends on the CDOM concentration where the salinity is zero (Binding and Bowers, 2003). With types of organic matter, number and duration of rainfall, change in the size of the basin, the slope will undoubtedly vary with geography and time.

This relationship is comparable to those obtained by the previous studies in the Clyde Sea (Mckee et al., 1999; Bowers et al., 2000) and in the PRE with the smaller slope of the regression 
Table 4: Salinity of samples on October 21, 2012 in the Lingding Bay of PRE.

\begin{tabular}{llllllllllllllllll}
\hline Station\# & $\mathbf{1}$ & $\mathbf{2}$ & $\mathbf{3}$ & $\mathbf{4}$ & $\mathbf{5}$ & $\mathbf{6}$ & $\mathbf{7}$ & $\mathbf{8}$ & $\mathbf{9}$ & $\mathbf{1 0}$ & $\mathbf{1 1}$ & $\mathbf{1 2}$ & $\mathbf{1 3}$ & $\mathbf{1 4}$ & $\mathbf{1 5}$ & 16 & 17 \\
\hline Salinity $(\%)$ & 14.18 & 15.35 & 14.76 & 17.33 & 17.26 & 18.66 & 18.61 & 17.85 & 17.85 & 17.99 & 16.37 & 16.35 & 15.83 & 15.78 & 15.67 & 15.98 & 16.45 \\
\hline
\end{tabular}

line between $a_{C D O M}(355)$ and salinity, which demonstrates that CDOM of the Lingding Bay of PRE is terrigenous (Chen et al., 2004; Hong et al., 2005).

Validation of the models for $a_{\text {CDOM }}(355)$ and salinity: To verify the performance of the MODIS 250-m models, the determination coefficients $\left(R^{2}\right)$, the mean relative error (MRE) and the root mean square error of salinity estimation (RMSE) were used for evaluation accuracy of the calibrated models. The best-fitting model for detecting marine intrusion was determined by comparison of the $R^{2}$, RMSE and MRE.

Salinity is used as the sole evaluation index for the models, because the CDOM absorption coefficient of water samples weren't measured on October 21, 2012 (Table 4). The field measured data was processed in the following way. First, the
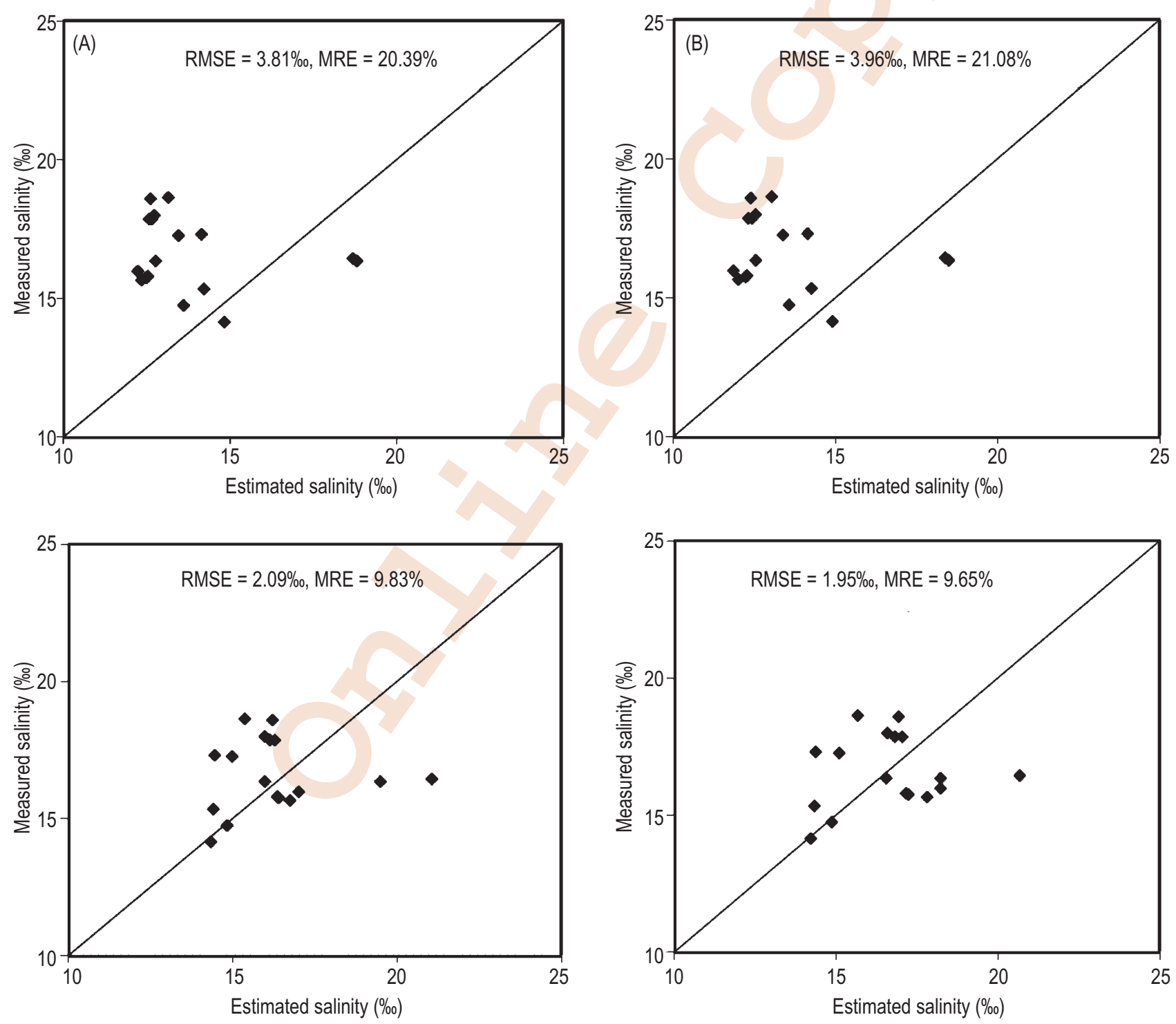

Fig. 5 : Scatter plots of measured vs. estimated salinity for the four models: $\mathrm{A}$, the linear model of $R_{r s}(\mathrm{~B} 2) / R_{r s}(\mathrm{~B} 1)$; $\mathrm{B}$, the linear model of sediment index; $\mathrm{C}$, the quadratic models of $R_{r s}(\mathrm{~B} 2) / R_{r s}(\mathrm{~B} 1)$; D, the quadratic models of sediment index. The RMSE and MRE of every model were calculated and presented in the figure using the independent dataset (the number of samples $(N)$ is 17 , and the salinity range is $14.18-18.66 \%$ ). 
480

L. Fang et al.: Evaluation of water salinity by MODIS 250-m imageries

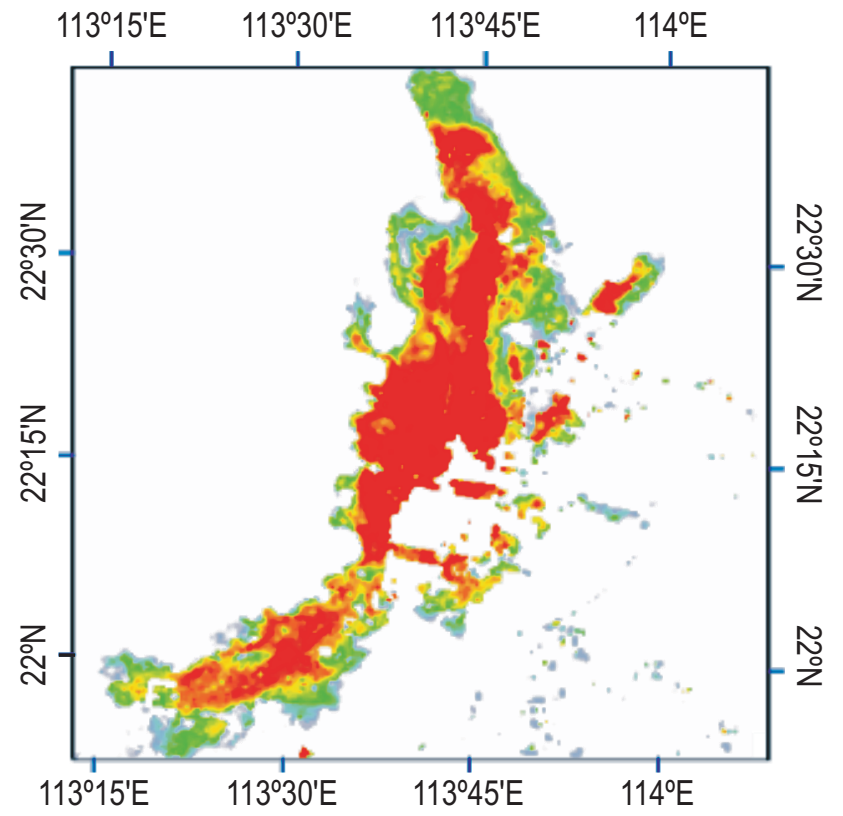

0

(A) 10.40, October 21, 2012

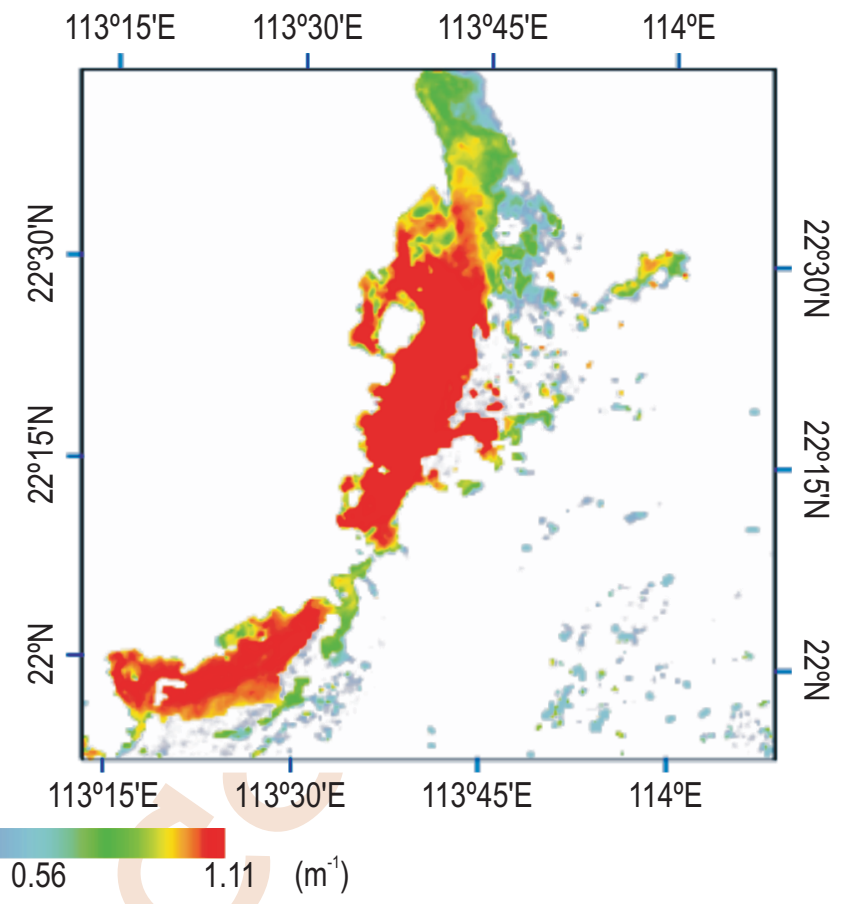

(B) 13.50, October 21, 2012

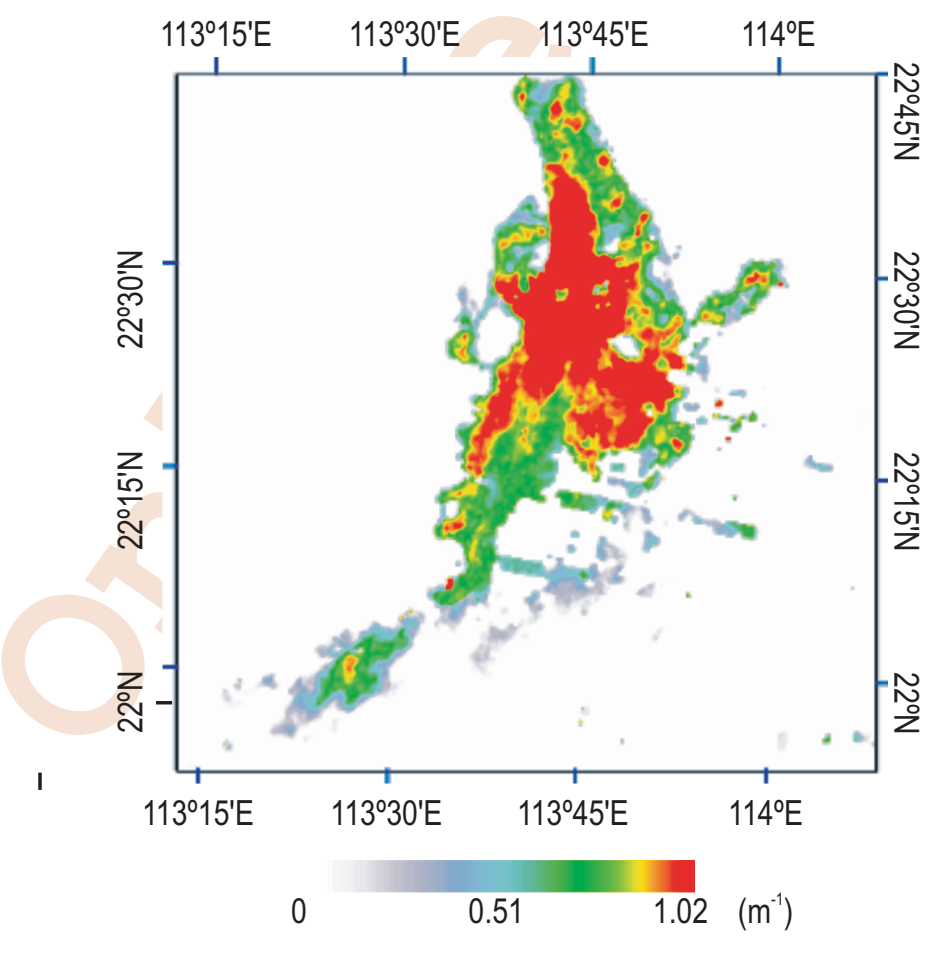

(C) 11:05, November 2, 2012

Fig. 6 : Mapping of $a_{\text {CDom }}(355)$ using the quadratic model of sediment index from MOD09 and MYD09 imageries with 250-meter spatial resolution in the PRE, China. 
reflectance of MODIS 250-m bands $\left(R_{r s}(\mathrm{Bi})\right)$ were simulated from the 17 reflectance $R_{r s}(I)$ measured on October 21, 2012, using the band response function. Second, the CDOM absorption coefficient at $355 \mathrm{~nm}\left(\mathrm{a}_{\text {CDOM }}(355)\right)$ was estimated based on the four models (Fig. 3(C-F)) in each sampling station. Finally, the corresponding salinity of each station was predicted using Eq.6. Based on another 17 samples, the validation of the calibrated models (Fig. 3(C-F)) are carried out as shown in Fig. 5(A-D).
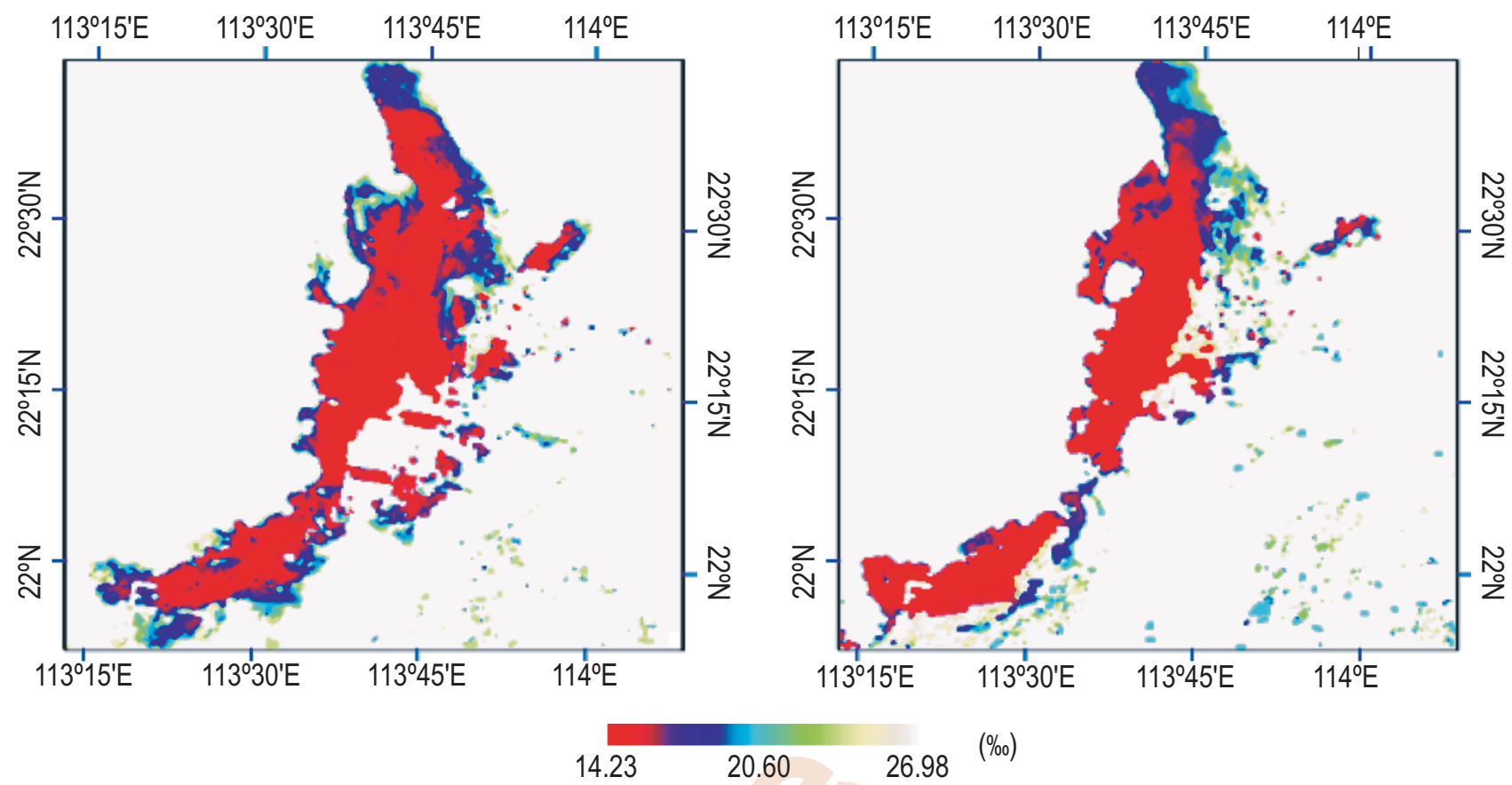

$(\%)$

(A) 10:40, October 21, 2012

(A) 13:50, October 21, 2012

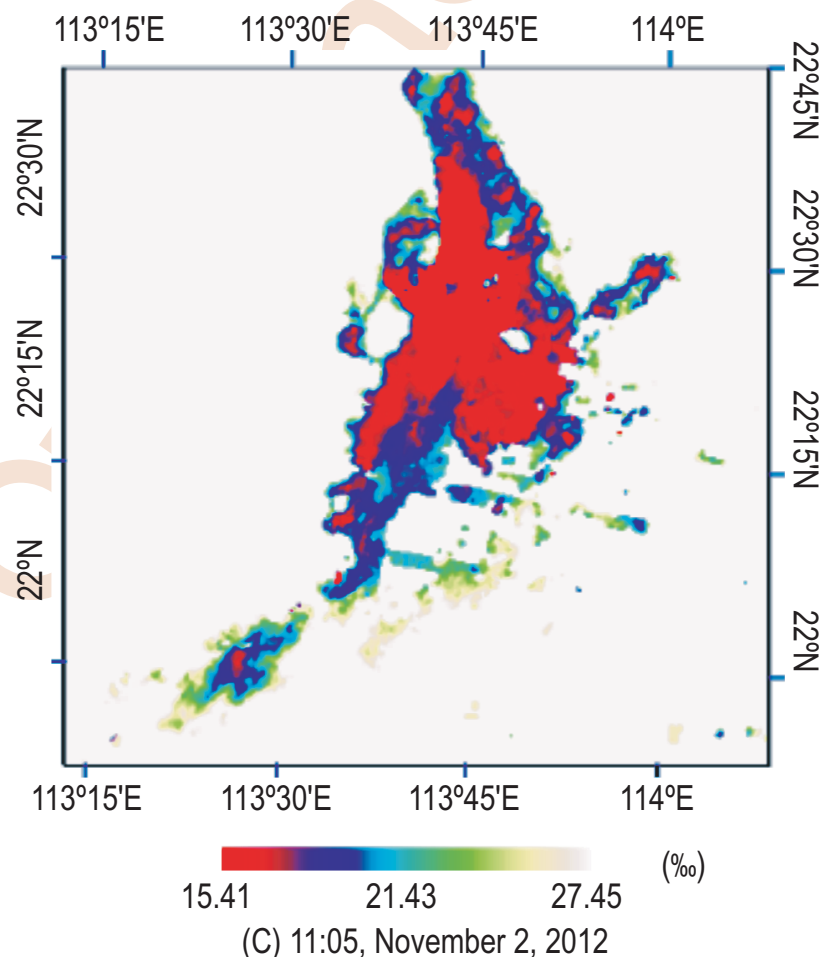

Fig. 7 : Mapping of salinity based on the reverse linear model of $a_{C D O M}(355)$ from MOD09 and MYD09 imageries with 250-meter spatial resolution in the PRE, China. 


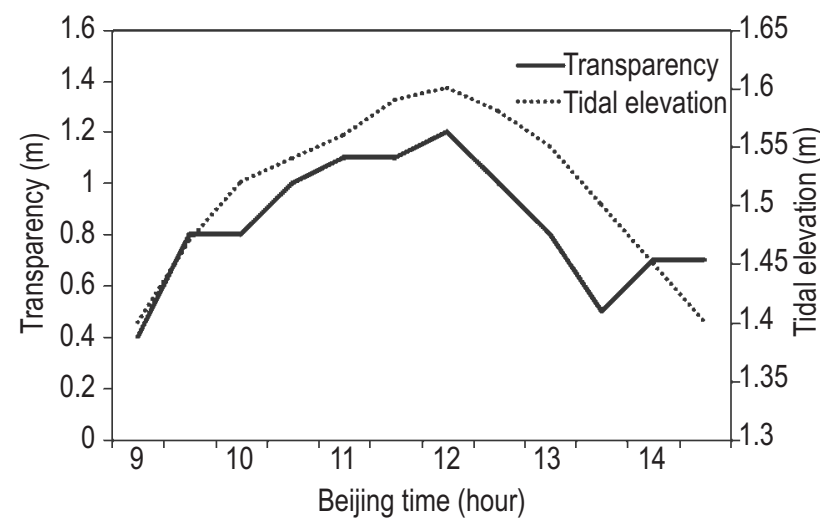

Fig. 8: Transparency changes of water measured from 9:30 to 14:30 on November 2, 2012 in the PRE (Corresponding tidal elevation was presented by dash.

Fig.5(A) presents salinity estimated based on the linear model of $R_{r s}(\mathrm{~B} 2) / R_{r s}(\mathrm{~B} 1)$. Fig.5(B)) presents salinity estimated based on the linear model of $\left(\left(R_{r s}(\mathrm{~B} 1)-R_{r s}(\mathrm{~B} 2)\right) /\left(R_{r s}(\mathrm{~B} 1)+R_{r s}(\mathrm{~B} 2)\right)\right.$. Fig. $5(C)$ and Fig. 5(D) show the results calculated by the quadratic models of band ratio and sediment index, respectively. From the comparison graphs of salinity estimated and measured, the salinity estimations calculated by the linear models of band ratio and sediment index were biased greatly. The salinity of most stations is underestimated. The MRE of the whole salinity range $(14.18-18.66 \%$ ) for the linear models of band ratio is $20.39 \%$, with RMSE $=3.81 \%$ (Fig. 5(A)). The MRE of the whole salinity range for the linear model of sediment index is $21.08 \%$, with RMSE $=3.96 \%$ (Fig. 5(B)). The salinity estimations calculated by the quadratic models of band ratio and sediment index were closer to the measured values. The MREs for the quadratic model of band ratio and sediment index are $9.83 \%$ and $9.65 \%$, and the RMSEs are $2.09 \%$ and $1.95 \%$, respectively.

The quadratic model of sediment index explained $66.9 \%$ of the absorption coefficient of CDOM variation, including 18 water samples for model calibration. Moreover, this quadratic model has got the least RMSE and MRE values based on the independent validation dataset (Fig. 5(D), $N=17$, RMSE = $1.95 \%$, MRE $=9.65 \%)$ as shown in Fig. $3(\mathrm{C}-\mathrm{F})$. Thus, the quadratic model of MODIS 250-m sediment index $\left(\left(R_{r s}(\mathrm{~B} 1)-R_{r s}\right.\right.$ $(\mathrm{B} 2)) /\left(R_{r s}(\mathrm{~B} 1)+R_{r s}(\mathrm{~B} 2)\right)$ is the optimal for monitoring of the CDOM absorption coefficient. Thus, the salinity values can be estimated furtherly based on the linear correlation between $a_{C D O M}$ (355) and salinity.

Mapping $\mathrm{a}_{\text {CDOM }}(355)$ and salinity using optimal models from MODIS imagery : According the results above (Figs. 3, 4 and 5), the quadratic model of MODIS 250-m sediment index and linear model of the absorption coefficients of CDOM, are considered as the optimal models for estimation of $a_{\text {CDOM }}$ (355) and salinity, respectively. The models were applied to the MODIS 250-m remote sensing images for validating, and $\mathrm{a}_{\mathrm{CDOM}}(355)$ and salinity values of PRE were retrieved on October 21, 2012 and November 2, 2012. The mapping results of $a_{\text {CDOM }}(355)$ were shown in Fig. 6.

Fig. 6 presents the inversion result of the coastal and inner Lingding Bay water of PRE, however, the result of outer Lingding Bay of PRE-is partially missing duo to cloud cover. In general, the absorption coefficients of CDOM values are higher in the Lingding Bay than outside area, and west of Lingding Bay than east region. The apparent off-shore and off-outlet decrease of $a_{\text {CDOM }}(355)$ means that the CDOM is brought by the Pearl River runoffs. In Fig.6, there is a great change in the $a_{\text {CDom }}(355)$ ranging from $0.07 \mathrm{~m}^{-1}$ to $1.11 \mathrm{~m}^{-1}$. The areas of higher absorption coefficients of CDOM were detected near Humen, Hengmen and Modaomen outlet where values are greater than $1 \mathrm{~m}^{-1}$. The area of lower values is away from the estuary. From Fig. 6(A) and (B), the simulated images are from the MODIS images on the same day at different times and show the dynamic CDOM changes in the PRE. The CDOM is more widely distributed in the Fig. 6(A) during the high tide, however the CDOM is concentrated in the outlets in the Fig.6(B) during the low tide. Some researchers demonstrate that the tide makes the turbidity of water higher (He et al., 2013; Li et al., 2003), and stronger interactions of runoff and tidal flow. Fig.8 show that the synchronization change of transparency and tidal elevation of water measured from 9:30 to 14:30 on November 2, 2012 in the PRE. Transparency of sampling water increases with tidal elevation increasing, vice versa. The dynamic changes of CDOM indicate that tidal elevation is key factor for it as the runoff and wind speed did not change (Gao et al., 2017; Wang et al., 2018; Fletemeyer et al., 2018). Additionally, the minor CDOM changes in Fig. 6 also indicates microtidal variation with average tidal ranging from 0.8 to $1.63 \mathrm{~m}$ in the PRE (Fang et al., 2010).

The salinity values were estimated based on the reverse linear correlation between $a_{\text {CDOM }}(355)$ and salinity. The results were shown in Fig. 7. Although opposite variation tendency of salinity distribution existed, the salinity values are lower in the Lingding Bay than outside region, and in the river outlet than outside of outlet. There is the significant off-outlet increase of salinity from Fig. 7. Fig. 7(B) presents an obvious boundary line of seawater and freshwater, which indicates weak interactions of runoff and tidal flow. According to tidal elevation data of October 21, 2012, Fig. 7(A) was imaged at around 10:40 h, when Lingding Bay is in the high tide, and Fig.7(B) was imaged at around 13:50 h, when Lingding Bay is in the low tide. So, the distribution of salinity is more uniform in Fig. 7(A) than Fig. 7(B) duo to tidal effect. Compared with the result on October 21, 2012, the salinity values are much higher (Fig. 7(C) on November 2, 2012. In Fig. 7(C), salinity show a large variation ranging from $15.41 \%$ to $27.45 \%$ o with a mean value of $19.36 \%$. The lowest salinity was on the east side of Qiao island where the salinity values under $16 \%$ were frequently found. Low salinity near Qiao island was probably caused by injection of a lot of runoff from Humen, JiaoMen, HongQiMen and HengMen outlets. The low salinity areas were 
Table 5: Comparison between MODIS derived and in situ measured salinity from seven in-situ samples on October 21, 2012 and three in situ samples on November 2, 2012.

\begin{tabular}{lllllllllll}
\hline Station\# & $\mathbf{1}$ & $\mathbf{2}$ & $\mathbf{3}$ & $\mathbf{4}$ & $\mathbf{5}$ & $\mathbf{6}$ & $\mathbf{7}$ & $\mathbf{8}$ & $\mathbf{9}$ & $\mathbf{1 0}$ \\
\hline Measured Salinity $(\%)$ & 20.11 & 19.69 & 19.62 & 15.35 & 14.76 & 17.33 & 17.26 & 18.66 & 16.35 & 16.45 \\
Estimated Salinity (\%) & 22.39 & 22.26 & 18.70 & 15.45 & 14.87 & 15.36 & 15.03 & 16.08 & 15.10 & 16.06 \\
\hline
\end{tabular}

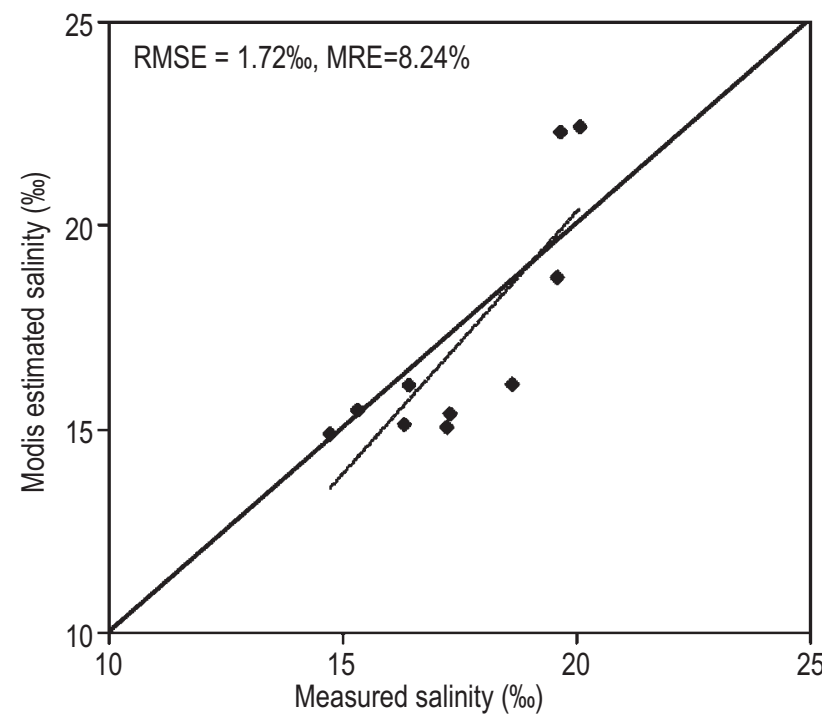

Fig. 9 : Correlation between the measured and MODIS estimated salinity. Data at 10 stations collected synchronous with Terra MODIS and Aqua MODIS imageries were used for validation of salinity. The best linear fit is presented by dashed line.

also in the shoal with shallow water depth, according to the sea graph of Lingding Bay. The salinity distribution of Lingding Bay is subject to tide, runoff, wind and water depth, shows the dynamic concentrations changes.

The MODIS 250-m salinity mapping was re-validated using in-situ measured data (table 5). Salinity data from 7 in-situ samples on October 21, 2012 and 3 in situ samples on November 2, 2012 selected within an hour's time difference between the satellite transit and synchronous measurement. The comparison graph of MODIS estimated salinity and in situ measured salinity (Fig.9) showed the good relationship between the two $\left(R^{2}=0.67\right)$. The comparison also presented high precision of salinity evaluation based on the two types of MODIS reflectance products (RMSE $=1.72 \%$, MRE $=8.24 \%$, and $N=10)$. Because of difficult and complex conditions for in situ water sampling, the change was little in optical characteristics of validation data set, with dynamic range of salinity from $14.76 \%$ to $20.11 \%$. The validation results present that the quadratic model of MODIS 250-m sediment index and the reverse linear model of $a_{\text {CDOM }}(355)$ were robust for estimation of $a_{\text {СDOM }}(355)$ and salinity, respectively in the Lingding Bay of PRE (Jasinski, 2017; Cruz Campas et al., 2017; Zhang etal., 2018).
This study developed the bio-optical models using field data and simulated MODIS bands to search the best models for salinity mapping from remote sensing in the Lingding Bay of PRE. It was found that there is a linear relationship between the CDOM absorption coefficient $\left(a_{C D O M}(355)\right)$ and band ratio of red light to other color based on data set on November 2, 2012, it demonstrated that the optical signature of CDOM was stronger compared to that of suspended particles in estuarine and coastal environment (Bowers et al., 2000). Further, the quadratic models of $R_{r s}(\mathrm{~B} 2) / R_{r s}(\mathrm{~B} 1)$ and $\left(R_{r s}(\mathrm{~B} 1)-R_{r s}(\mathrm{~B} 2)\right) /\left(R_{r s}(\mathrm{~B} 1)+R_{r s}(\mathrm{~B} 2)\right)$ had the higher calibration accuracy among all models, explaining more than $66 \%$ of the CDOM variation in the PRE. It was also found that the $a_{\text {CDOM }}(355)$ is importantly related to salinity in the $\operatorname{PRE}\left(R^{2}=0.83, N=18, P<0.001\right)$. Salinity decline linearly with the raising of $a_{C D O M}(355)$, indicating that CDOM originated from fresh water runoff in the Lingding Bay of PRE. The models were validated by the independent data set on October 21, 2012. The quadratic model of sediment index has got the least RMSE and MRE values (RMSE $=1.95 \%$, $M R E=9.65 \%, N=17$ ), and was the optimal model for simulation of the CDOM absorption coefficient in the Lingding Bay of PRE.

The MODIS 250-m images on 21 October 2012 and 2 November 2012 aboard on Terra, 21 October 2012 aboard on Aqua, were selected to evaluate the performance of optimal salinity estimation models in the PRE. The result presented rationality of salinity distribution. The salinity values are lower in the Lingding Bay than outside region, and in the river outlet than outside of outlet. The MODIS 250-m salinity mapping was revalidated using in-situ measured data, which was collected within an hour's time difference between the satellite transit and synchronous measurement $(\mathrm{RMSE}=1.72 \%, \mathrm{MRE}=8.24 \%$, and $N=10$ ). The quadratic model of sediment index and the reverse linear model of $a_{\text {CDOM }}(355)$ can be used for monitoring timevariation in $\mathrm{CDOM}$ concentration and salinity respectively due to tidal fluctuation, which proves the detection ability of MODIS 250$\mathrm{m}$ in estuarine and coastal waters in the Lingding Bay. Results from this work demonstrated the rationale behind the sediment index model and reverse linear model. Finding also revealed the robustness of these algorithms for the absorption coefficient of CDOM and salinity estimation based on in situ and MODIS 250-m spectral data in the turbid estuary of PRE. Next, in situ datasets with a wider salinity range and more sampling data would be used for validation of MODIS 250-m salinity mapping, this can better evaluate the accuracy and applicability of the salinity models by 
remote sensing technology.

\section{Acknowledgments}

This research was partly funded by the National Natural Science Fund Grant (41201338, 61672372 and 61472211), "333 Project" of Jiangsu Province (BRA2015096) and Jiangsu Government Scholarship for Overseas Studies. We thank Chuqun Chen and Shiliang Wu for their help in field data sampling and analysis. We also thank USGS for providing the MOD09 and MYD09 L2 data product.

\section{References}

Abbas, P., Y.Z.H.Y. Hashim and H.M. Salleh: Cytotoxic effects and response surface optimization of solvent extraction of crude extracts from Aquilaria subintegra uninfected branch. Sci. Herit. J., $2,10-15(2018)$.

Binding, C.E., D.G. Bowers and E.G. Mitchelson-Jacob: Estimating suspended sediment concentrations from ocean colour measurements in moderately turbid waters; the impact of variable particle scattering properties. Rem. Sens Environ., 94, 373-383 (2009).

Binding, C.E. and D.G. Bowers: Measuring the salinity of the Clyde Sea from remotely sensed ocean colour. Estu. Coa. Shelf Sci., 57, 605611 (2003)

Bowers, D.G., G.E.L. Harker, P.S.D. Smith and P. Tett: Optical properties of a region of freshwater influence (The Clyde Sea). Estu. Coas. Shelf Sci., 50, 717-726 (2000)

Bricaud, A., A. Morel and L. Prieur: Absorption by dissolved organic matter of the Sea (Yellow Substance) in the UV and Visible domains. Limnol. Oceanogr., 26, 43-53 (1981).

Bricaud, A., A.M. Ciotti and B. Gentili: Spatial temporal variations in phytoplankton size and colored detrital matter absorption at global and regional scales, as derived from twelve years of SeaWiFS data (1998-2009). Global Biogeochem. CY., 26, GB2010 (2012).

Castillo, C.E. and D.R.L. Miller: On the use of ocean color remote sensing to measure the transport of dissolved organic carbon by the Mississippi River Plume. Rem. Sens. Environ., 112, 836-844 (2007).

Chen, C.Q., Z.L. Pan and P. Shi: Simulation of sea water reflectance and its application in retrieval of yellow substance by remote sensing data. J. Trop. Oceanogr., 22, 33-39 (2003).

Chen, S.S., L.F. Chen, Q.H. Liu, X. Li and Q. Tan: Remote sensing and GIS-based integrated analysis of coastal changes and their environmental impacts in Lingding Bay, Pearl River Estuary, South China. Ocean Coast Manage, 48, 65-83 (2005).

Chen, Z., Y. Li and J. Pan: Distributions of the optical properties of colored dissolved organic matter and dissolved organic carbon in the Pearl River. Cont. ShelfRes., 24, 1845-1856 (2004).

Chuanlei, L., L. Guomin, H. Yuanfei and W. Guojun: Research on mental health status and the relationship between spiritual belief and self - harmony. Sci. Herit. J., 2, 16 -20 (2018).

Cruz Campas, M.,A.G. Villalba and L.R. E. Ramirez: Air quality regarding metals $(\mathrm{Pb}, \mathrm{Cd}, \mathrm{Ni}, \mathrm{Cu}, \mathrm{Cr})$ and relationship with respiratory health: Caso Sonora, Mexico. Revista Internacional De Contaminacion Ambiental, 33, 23-34 (2017).

D'Sa, E.J., J.B. Zaitzeff and R.G. Steward: Monitoring water quality in
Florida Bay with remotely sensed salinity and in situ bio-optical observations. Int. J. Remote Sens, 21, 811-816 (2000).

D'Sa, E.J., R.L. Miller and C.C. Del: Bio-optical properties and ocean color algorithms for coastal waters influenced by the Mississippi River during a cold front. Appl Optics, 45, 7410-7428 (2006).

D'Sa, E.J.R.L. Miller: Bio-optical properties in waters influenced by the Mississippi River during low flow conditions. Remote Sens. Environ., 84, 538-549 (2003).

Doerffer, R.H. Schiller: The MERIS case 2 water algorithm. Int. J. Remote Sens., 28, 517-535 (2007).

Fang, L.G., S.S. Chen, H.Q. Wang, J.P. Qian and L.X. Zhang: Detecting marine intrusion into rivers using EO-1 ALI satellite imagery: Modaomen Waterway, Pearl River Estuary, China. Int. J. Remote Sens., 31, 4125-4146 (2010)

Fang, L.G., S.S. Chen, L. Dong and H.L. Li: Use of reflectance ratios as a proxy for coastal water constituent monitoring in the Pearl River Estuary. Sensors-Basel, 9, 656-673(2009).

Fletemeyer, J., J. Hearin, B. Haus and A. Sullivan: The impact of sand nourishment on Beach Safety. J. Coastal Res., 34, 1-5 (2018).

Gao, W., Y. Wang, B. Basavanagoud and M.K. Jamil: Characteristics studies of molecular structures in drugs. Saudi Pharm. J., 25, 580586 (2017).

Hale, G.M. and M.R. Querry: Optical-constants of water in 200-Nm to 200-Mum wavelength region. Appl Optics, 12, 555-563 (1973).

He, X., Y. Bai, D. Pan, N. Huang, X. Dong, J. Chen, C.T.A. Chen and Q. Cui: Using geostationary satellite ocean color data to map the diurnal dynamics of suspended particulate matter in coastal waters. Remote Sens. Environ., 133, 225-239 (2013).

Hong, H., J. Wu, S. Shang and C. Hu: Absorption and fluorescence of chromophoric dissolved organic matter in the Pearl River Estuary, South China. Mar. Chem., 97, 78-89 (2005).

Hu, C., Z. Chen, T.D. Clayton, P. Swarzenski, J.C. Brock and F.E. Muller Karger: Assessment of estuarine water-quality indicators using MODIS medium-resolution bands: Initial results from Tampa Bay, FL. Remote Sens. Environ., 93, 423-441 (2004).

Jamal, F., A.M. Khattak, G.A. Khan and S. Abdullah: Five separation axioms in quad soft non-linear structure. Acta Sci. Malays., 2, 1420 (2018).

Jasinski, R.: Problems of the starting and operating of hydraulic components and systems in low ambient temperature (part v) methods ensuring correct start-up of hydraulic components of ship's onboard devices in low ambient temperatures. Polish Maritime Res., 24, 47-56 (2017).

Jerlov, N.G.: Optical oceanography, Elsevier, Amsterdam, p. 194 (1968).

Johannessen, S.C., W.L. Miller and J.J. Cullen: Calculation of UV attenuation and colored dissolved organic matter absorption spectra from measurements of ocean color. J. Geophy. Res. Oceans, 108, 3301-3313 (2003).

Kibria, A.A., Kamrunnessa and M.M. Rahman: Extraction and evaluation of phytochemicals from Green Coconut (Cocos nucifera) shell. Malays. J. Halal Res., 1, 19-22 (2018).

Lee, Z., R. Arnone, C. Hu, P.J. Werdell and B. Lubac: Uncertainties of optical parameters and their propagations in an analytical ocean color inversion algorithm. APPL Optics, 49, 369-381 (2010).

Li, Z.H., X.K. Ke, Q. Wang and J.H. Gao: Characteristics of water and sediment transport in the Qiongzhou Strait. Geograph. Res., 22, 151-159 (2003).

Mannino, A., M.E. Russ and S.B. Hooker: Algorithm development and validation for satellite-derived distributions of $\mathrm{DOC}$ and $\mathrm{CDOM}$ in 
the U.S. Middle Atlantic Bight. J. Geophys. Res. Oceans, 113, C7051 (2008).

Mannino, A., M.G. Novak, S.B. Hooker, K. Hyde and D. Aurin: Algorithm development and validation of $\mathrm{CDOM}$ properties for estuarine and continental shelf waters along the northeastern U.S. coast. Remote Sens. Environ., 152, 576-602 (2014).

Mao, Q., P. Shi, K. Yin, J. Gan and Y. Qi: Tides and tidal currents in the Pearl River Estuary. Cont. ShelfRes., 24, 1797-1808 (2004).

Mckee, D., A. Cunningham and K. Jones: Simultaneous measurements of fluorescence and beam attenuation: Instrument characterization and interpretation of signals from stratified coastal waters. Estuarine Coastal Shelf Sci., 48, 51-58 (1999).

Mobley, C.D.: Estimation of the remote-sensing reflectance from abovesurface measurements. APPL Optics, 38, 7442-7455 (1999).

Monahan, E.C. and M.J. Colour: UV absorbance and salinity of the surface waters of the west coast of Ireland. Nature, 274, 782-784 (1978).

Muerller, J.L. and G.S. Fargion: Ocean optics protocols for Satellite Ocean color sensor validation. 5, 171-179 (2002).

Naik, P., E.J. D'Sa, M. Grippo, R. Condrey and J. Fleeger: Absorption properties of shoal-dominated waters in the Atchafalaya Shelf, Louisiana, USA. Int. J. Remote Sens., 32, 4383-4406 (2011).

Petus, C., G. Chust, F. Gohin, D. Doxaran, J.M. Froidefond and Y. Sagarminaga: Estimating turbidity and total suspended matter in the Adour River plume (South Bay of Biscay) using MODIS 250-m imagery. Cont. ShelfRes., 30, 379-392 (2010).

Pope, R.M. and E.S. Fry: Absorption spectrum (380-700 nm) of pure water. II. Integrating cavity measurements. Appl. Optics, 36, 8710 8723 (1997).

Razzak, M.A., M.A. Islam, M.H. Rahman, M.A. Sathi and Md Atikuzzamman: Screening of lentil germplasm against Stemphylium Blight by observing disease reaction in three different stages. Malays. J. Halal. Res., 1, 15-18

Schaeffer, B.A., R.N. Conmy, A.E. Duffy, J. Aukamp, D.F. Yates and G. Craven: Northern Gulf of Mexico estuarine coloured dissolved organic matter derived from MODIS data. Int. J. Remote Sens., 36, 2219-2237 (2015).

Shanmugam, P.: New models for retrieving and partitioning the colored dissolved organic matter in the global ocean: Implications for remote sensing. Remote Sens Environ., 115, 1501-1521 (2011).

Smith, R.C. and K.S. Baker: Optical properties of the clearest natural waters (200-800 nm). APPL Optics, 20, 177-184 (1981).

Tang, J., G. Tian, X. Wang, X. Wang and Q. Song: The methods of water spectra measurement and analysis !: Above-water method. J. Remote Sens., 8, 37-44 (2004).

Tilstone, G.H., S.W.M. Peters, H.J.V.D. Woerd, M.A. Eleveld, K. Ruddick, W. Schönfeld, H. Krasemann, V. Martinezvicente, D. Blondeaupatissier and R. Röttgers: Variability in specificabsorption properties and their use in a semi-analytical ocean colour algorithm for MERIS in North Sea and Western English Channel Coastal Waters. Remote Sens. Environ., 118, 320-338 (2012).

Wang, M., D.Q. Zhang, J. Su, J.W. Dong and S.K. Tan: Assessing hydrological effects and performance of low impact development practices based on future scenarios modeling. J. Clean Prod., 179, 12-23 (2018).

Werdell, P.J., B.A. Franz, S.W. Bailey, G.C. Feldman, E. Boss, V.E. Brando, M. Dowell, T. Hirata, S.J. Lavender and Z.P. Lee: Generalized ocean color inversion model for retrieving marine inherent optical properties. APPL Optics, 52, 2019-2037 (2013).

Xia, X.M., Y. Li, H. Yang, C.Y. Wu, T.H. Sing and H.K. Pong: Observations on the size and settling velocity distributions of suspended sediment in the Pearl River Estuary, China. Cont Shelf Res., 24, 1809-1826 (2004).

Xiao, D. and Y. Liu: The evaluation indexes of scientific and technological achievements in Jiangxi Province, China. Acta Sci. Malays., 2, 0809 (2018).

Ye, L.K. and D. Preiffer: Studies of 2D and 3D numerical simulation of Kelvin tide wave in Nei Lingdingyang at Pearl River Estuary. Ocean Eng., 8, 33-44 (1990).

Yin, J.P., Y.S. Wang, J.R. Xu, C.C. Sun, F.Q. Zhang and L. He: Influences of saline water intrusion on environmental elements in outlet section of Zhujiang River. J. Tropical Oceanography, 25, 79-84 (2006).

Zhang, N., C. Zhou, W. Xia and A.V. Nguyen: Volatilization of mercury in coal during conventional and microwave drying and its potential guidance for environmental protection. J. Clean Prod., 176, 1-6 (2018). 